\title{
"Ultra-sensitive" cardiac troponins: Requirements for effective implementation in clinical practice
}

\author{
Giuseppe Lippi*1, Fabian Sanchis-Gomar ${ }^{2,3,4}$ \\ ${ }^{1}$ Section of Clinical Biochemistry, University of Verona, Verona, Italy \\ ${ }^{2}$ Leon H. Charney Division of Cardiology, New York University School of Medicine, New York, USA \\ ${ }^{3}$ Department of Physiology, Faculty of Medicine, University of Valencia, Valencia, Spain \\ ${ }^{4}$ INCLIVA Biomedical Research Institute, Valencia, Spain \\ *Corresponding author: giuseppe.lippi@univr.it
}

\begin{abstract}
The measurement of cardiac troponins, either cardiac troponin I or T, has become the culprit of clinical decision making in patients with suspected acute coronary syndrome (ACS), especially in those with non-ST elevation myocardial infarction (NSTEMI). The leading analytical mainstays of cardiac troponin immunoassays include the limit of blank $(\mathrm{LOB})$, limit of detection $(\mathrm{LOD})$, functional sensitivity, the $99^{\text {th }}$ percentile of a healthy reference population, along with the percentage of "ostensibly healthy" subjects displaying measurable values $<99^{\text {th }}$ percentile. The latest generation of cardiac troponin immunoassays, conventionally defined as "high-sensitive" (HS), is characterized by a LoD over 100-fold lower compared to the first commercialized techniques and a percentage of measurable values consistently $>50 \%$ in the general healthy population. The very recent commercialization of methods with further improved analytical sensitivity (i.e., "ultra-sensitive" assays), which allow to measure cardiac troponin values in the vast majority of healthy subjects, is now challenging the diagnostic paradigm based on early rule-out of subjects with cardiac troponin values comprised between the $99^{\text {th }}$ percentile and LoD. New diagnostic strategies, entailing assay-specific cut-offs, must hence be developed and validated in large multicenter studies. The aim of this article is to provide an update on commercially available HS and "ultra"-sensitive techniques for measuring cardiac troponins, along with possible implications of increasingly enhanced analytical sensitivity on diagnostic algorithms for evaluating patients with suspected ACS.
\end{abstract}

Keywords: cardiac troponin; myocardial infarction; acute coronary syndrome; diagnostics

\section{Introduction}

Despite many efforts made through the adoption of widespread preventive strategies, both morbidity and mortality for acute coronary syndrome (ACS) remain extremely high. Thus, myocardial ischemia has become one of the leading health care challenges worldwide (1). Unlike many other human diseases, the diagnostic approach for patients with suspected ACS has undergone sizable and revolutionary changes since the release of the first diagnostic criteria by the World Health Organization in the early 1970s (2). Irrespective of the presence of typical signs and symptoms of myocardial ischemia and suggestive electrocardiographic
(ECG) abnormalities, the measurement of cardiac troponins (cTns), either cardiac troponin I (cTnl) or cardiac troponin $\mathrm{T}$ (cTnT), has become the culprit of making a specific clinical decision, particularly for diagnosing non-ST elevation myocardial infarction (NSTEMI) $(3,4)$. Very recent evidence, combining organization and economic endpoints with diagnostic efficiency, also confirms that the measurement of additional biomarkers, such as the creatine kinase isoenzyme MB (CK-MB), impose a considerable financial burden for the health care system, without providing incremental value to patient care (5). 


\section{Clinical use of high-sensitivity immunoassays}

The universally agreed analytical mainstays of cTn testing are summarized in Tables 1 and 2, and substantially include limit of detection (LoD), limit of blank (LoB), functional sensitivity (also known as "Limit of Quantitation"; LoQ) and the $99^{\text {th }}$ percentile of a healthy reference population (6-8).

The development and commercialization of cTn immunoassays started nearly 40 years ago, and progressed with the release of methods character- ized by gradually enhanced analytical performance, which are now gradually and irreversibly replacing the former generation of "contemporary-sensitive" techniques (8). For example, the first-generation cTn immunoassays was characterized by LoD of approximately $500 \mathrm{ng} / \mathrm{L}$ and $0 \%$ of measurable values (i.e., concentration > LoD) in healthy subjects, while the latest generation of immunoassays is characterized by a LoD over 100fold lower compared to the original techniques and a percentage of measurable values typically $>$ $50 \%$ (9). A substantial revolution has followed the

TABLE 1. Analytical quality specifications of cardiac troponin immunoassays

\begin{tabular}{|c|c|}
\hline Analytical quality specification & Description \\
\hline LoB & $\begin{array}{l}\text { Lowest signal generated in a fluid (i.e., typically the buffer or diluent of the assay) } \\
\text { with zero cTn concentration. }\end{array}$ \\
\hline LoD & $\begin{array}{l}\text { Value generated in a biological sample with the lowest measurable cTn } \\
\text { concentration. }\end{array}$ \\
\hline LoQ & Minimal concentration of $c T n$ that can be measured with $\leq 10 \%$ imprecision. \\
\hline 99 $9^{\text {th }}$ percentile & $\begin{array}{l}\text { Value of cTn corresponding to the } 99^{\text {th }} \text { percentile of a reference population of } \\
\text { ostensibly healthy subjects. }\end{array}$ \\
\hline $\begin{array}{l}\text { Percentage of measurable values in healthy } \\
\text { subjects }\end{array}$ & $\begin{array}{c}\text { Percentage of cTn values }<99^{\text {th }} \text { percentile that can be obtained in a reference } \\
\text { population of ostensibly healthy subjects. }\end{array}$ \\
\hline
\end{tabular}

cTn - cardiac troponin. LoB - limit of blank. LoD - limit of detection. LoQ - limit of quantitation (i.e. functional sensitivity).

TABLE 2. Cardiac troponin immunoassay designations

\begin{tabular}{|c|c|}
\hline \multicolumn{2}{|c|}{ Assay imprecision (\%) at a value corresponding to the $99^{\text {th }}$ percentile } \\
\hline$<10$ & Guideline acceptable \\
\hline $10-20$ & Clinically useable \\
\hline$>20$ & Not acceptable \\
\hline \multicolumn{2}{|c|}{ Percentage $(\%)$ of measurable values $<99^{\text {th }}$ percentile in healthy subjects } \\
\hline$<50$ & Contemporary-sensitive (CS) - Level 1 \\
\hline $50-75$ & First-generation high-sensitive (HS) - Level 2 \\
\hline $75-95$ & Second-generation high-sensitive (HS) - Level 3 \\
\hline$>95$ & Third-generation high-sensitive (HS) - Level 4 \\
\hline$\sim 99-100$ & Latest-generation high-sensitive (HS) - Level 5 \\
\hline \multicolumn{2}{|c|}{ Ratio between $99^{\text {th }}$ percentile and LoD } \\
\hline$<1$ & Clinically useable, high-sensitive (HS) \\
\hline$\geq 10$ & Extremely high-sensitive (HS) \\
\hline$\geq 20$ & Ultra-sensitive (US) \\
\hline
\end{tabular}

LoD - limit of detection. $99^{\text {th }}$ percentile $-99^{\text {th }}$ percentile of a reference healthy population. Modified from (8). 
introduction of these so-called "high-sensitivity" (HS) immunoassays, driven by the recent evidence that patients with values of both cTnl and cTnT comprised between the LoD and the $99^{\text {th }}$ percentile (i.e., $>$ LoD and $<99^{\text {th }}$ percentile) or between the functional sensitivity of the immunoassay and the $99^{\text {th }}$ percentile (i.e., $>$ LoQ and $<99^{\text {th }}$ percentile) have a higher risk of unfavorable clinical outcomes (both total and cardiovascular) compared to those with lower values (i.e., displaying cTn values < LoD or < LoQ) (10-15). Notably, such an enhanced risk of adverse events apparently lasts for a longer period after evaluation in the emergency rooms, since patients with values comprised between the $99^{\text {th }}$ percentile and LoD (or the functional sensitivity) also have an increased rate of 30day major adverse cardiovascular events (MACE). According to this paradigm, new diagnostic algorithms no longer use the $99^{\text {th }}$ percentile as the reference diagnostic threshold, but implement lower cTn cut-offs (i.e., conventionally identified with LoD or with the functional sensitivity) and entail shorter-time serial testing (i.e., between 1 and 2 hours after baseline assessment, rather than 3 and 6 hours afterwards) (16-21). The efficiency of this strategy for rapid rule-out of ACS and for identification of patients with enhanced risk of 30-day MACE has already been proven in a consistent number of studies, and it is therefore predictable that this strategy may soon become the standard of care $(10-15,22)$. Notably, the considerably improved analytical performance of the new generation of cTn HS immunoassays may also allow introducing an additional "functional" classification of the methods, based on the ratio between the $99^{\text {th }}$ percentile and LoD (Table 2). In clinical and labora- tory practice, the larger the $99^{\text {th }}$ percentile/LoD ratio, the higher the probability to identify subjects with "measurable" values will be.

At the time of publication of this article, four fullyautomated HS immunoassays are commercially available and their analytical performance is summarized in Table 3 (three for measuring cTnl and one for measuring cTnT, respectively) (23-27). Although these techniques display different analytical performance and designation according to the conventional criteria of imprecision and analytical sensitivity, they are all characterized by a $>1$ ratio between the $99^{\text {th }}$ percentile and LoD (Table 3), thus making them clinically useable even when adopting the new diagnostic algorithms encompassing rule-out and short-time serial testing based on diagnostic thresholds corresponding to either the LoD or the functional sensitivity $(7,8)$. Whether classifying the assays as clinically useable HS, extremely HS or "ultra-sensitive" (US) will determine additional clinical advantages for early rule-in or rule-out of ACS, or for predicting the risk of 30-day MACE, remains to be demonstrated, since no comparison studies have been published so far. Nevertheless, improving further the analytical sensitivity of these methods (i.e., lowering both the LoD and functional sensitivity), may also challenge the new diagnostic paradigm of early ruleout of subjects with cTn values comprised between the $99^{\text {th }}$ percentile and the LoD. Interestingly, the proportion of population with values $<99^{\text {th }}$ percentile and $>$ LoD has increased from $32 \%$ with Roche HS-cTnT to $97 \%$ with Beckman Coulter HScTnl (Figure 1), thus generating new practical dilemmas: is it plausible that all the $97 \%$ ostensibly healthy subjects showing Beckman Coulter HS-cT-

TABLE 3. Analytical performance of the four fully-automated high-sensitive cardiac troponin immunoassays commercially available

\begin{tabular}{ccccccccc}
\hline Manufacturer & Troponin & Platform & $\begin{array}{c}\text { LoB } \\
\text { (ng/L) }\end{array}$ & $\begin{array}{c}\text { LoD } \\
\text { (ng/L) }\end{array}$ & $\begin{array}{c}\text { CV10\% } \\
\text { (ng/L) }\end{array}$ & $\begin{array}{c}\text { 99th percentile } \\
\text { (ng/L) }\end{array}$ & $\begin{array}{c}\text { Ratio 99th } \\
\text { percentile/ } \\
\text { LoD }\end{array}$ & $\begin{array}{c}\text { Measurable } \\
\text { values }> \\
\text { LoD (\%) }\end{array}$ \\
\hline $\begin{array}{c}\text { Beckman Coulter } \\
\text { Siemens }\end{array}$ & CTnl & Access & 0.1 & 0.3 & 1.3 & 16 & 53 & 97 \\
Abbott & CTnl & ADVIA Centaur & 0.5 & 2.2 & 2.7 & 48 & 22 & $80-95$ \\
Roche & CTnl & ARCHITECT & $0.7-1.3$ & $1.1-1.9$ & 5.6 & 19 & $10-17$ & $57-75$ \\
\hline
\end{tabular}

cTnI - cardiac troponin I. CTnT - cardiac troponin T. LoB - limit of blank. LoD - limit of detection. CV10\% - value with $\leq 10 \%$ analytical imprecision. 


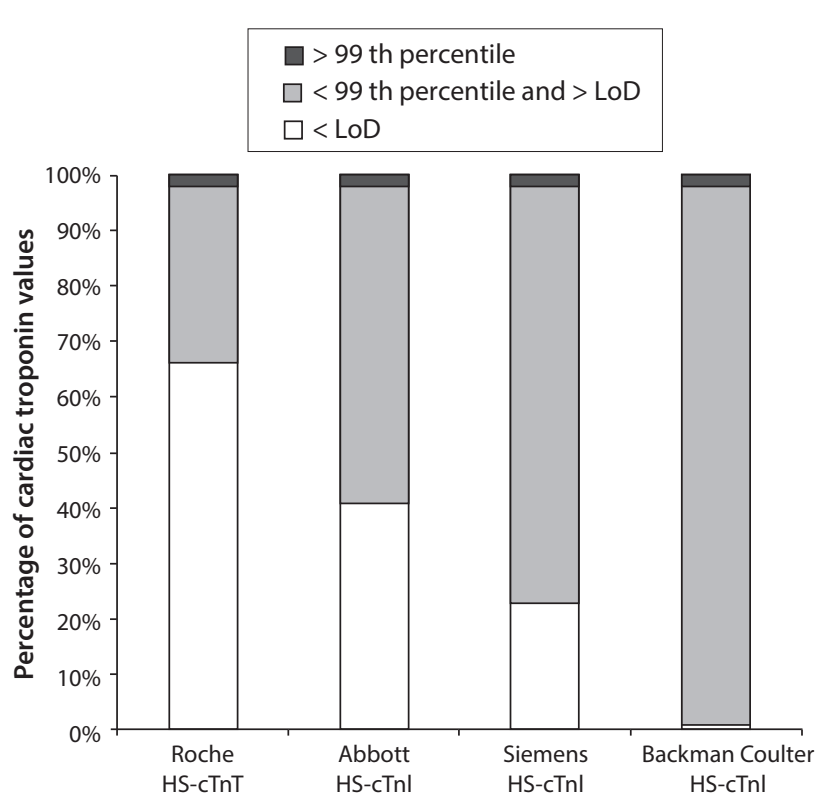

Figure 1. Percentage of measurable values of cardiac troponin in healthy population.

HS-cTnT - high sensitive cardiac troponin T. HS-cTnl - high sensitive cardiac troponin I. LoD - limit of detection. 99th percentile - 99th percentile of a reference healthy population.

$\mathrm{nl}$ values between the $99^{\text {th }}$ percentile and the LoD should be considered at increased risk of ACS or 30-day MACE compared to the remaining 3\% of the population displaying unmeasurable values? And, even more challenging, how should these subjects be managed? Quite understandably, the new rule-out strategies based on LoD or functional sensitivity values as diagnostic cut-offs have been clinically validated using the former HS Roche HS-cTnT and Abbott HS-cTnl immunoassays, which display a $99^{\text {th }}$ percentile/LoD ratio of 3 and $10-17$, respectively $(23,24)$. Evidence has been provided showing that the standardization of cTn immunoassays is still an unmet target, even after harmonization with common calibrators, so that diagnostic protocols validated using one cTn immunoassay may be inefficient when another technique is used (28). Notably, the two most recent Siemens and Beckman Coulter HS-cTnl immunoassays are characterized by a $99^{\text {th }}$ percentile/LoD ratio $>20$, and are hence more analytically sensitive. This would require developing specific algorithms for these methods.

\section{Diagnostic algorithms with "ultra-sensitive" techniques}

Given that a significant proportion of subjects with $c T n$ values $<99^{\text {th }}$ percentile are at enhanced risk of adverse cardiovascular events, the use of LoD or functional sensitivity as diagnostic thresholds for early rule-out will be no longer feasible due to the obvious increased rate of false positive results using the so-called "US" techniques (Figure 1). The decrease of the positive predictive value will likely be magnified as long as the analytical performance of the current immunoassays is improved further, or when newer and even more analytically sensitive techniques are commercialized. For example, a recent study aimed to investigate the analytical performance of the new Sgx cTnl Assay (Singulex Inc., Alameda, USA) reported that the LoB, LoD and functional sensitivity of this assay are $0.02,0.08$ and $0.53 \mathrm{ng} / \mathrm{L}$, whilst measurable cTnl concentrations could be observed in as many as 99.5\% of healthy subjects (29). Paradoxically, these considerations pave the way to turn back the clock to nearly 40 years ago, when the strategy used for identifying the most efficient diagnostic thresholds of cTns was based on receiver operating characteristics (ROC) curve analysis (Figure 2). Indeed, the new cTn cut-offs for "US" technique will need to combine the best diagnostic performance at patient presentation with the risk of 30-day MACE, yielding a cTn value in the lower end of concentrations comprised between the $99^{\text {th }}$ percentile and the LoD. Although the timing of serial sampling after patient presentation should also be defined with large (and possibly multicenter) clinical studies, it is predictable that $0 \mathrm{~h} / 1 \mathrm{~h}$ or $0 \mathrm{~h} / 2 \mathrm{~h}$ time points may be efficient, reliable and safe using "US" techniques, since the reference delta cTn variation selected for optimal ruling-out or ruling-in ACS will now be characterized by excellent performance in terms of analytical imprecision (i.e., much lower than 10\%). Therefore, the less specificity of "US" techniques, especially when using low diagnostic cut-offs, will be probably overcome by the advantage of enabling a safer and earlier rule out of ACS. More specifically, recent studies showed that the use of a low cTn cut-off, equal or close to the LoD of the immunoassay, may allow adopting 


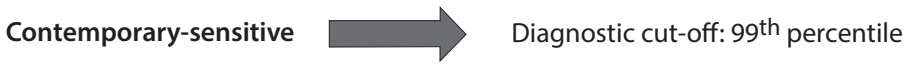

High-sensitive $\longrightarrow$ Diagnostic cut-off: LoD or CV10\%

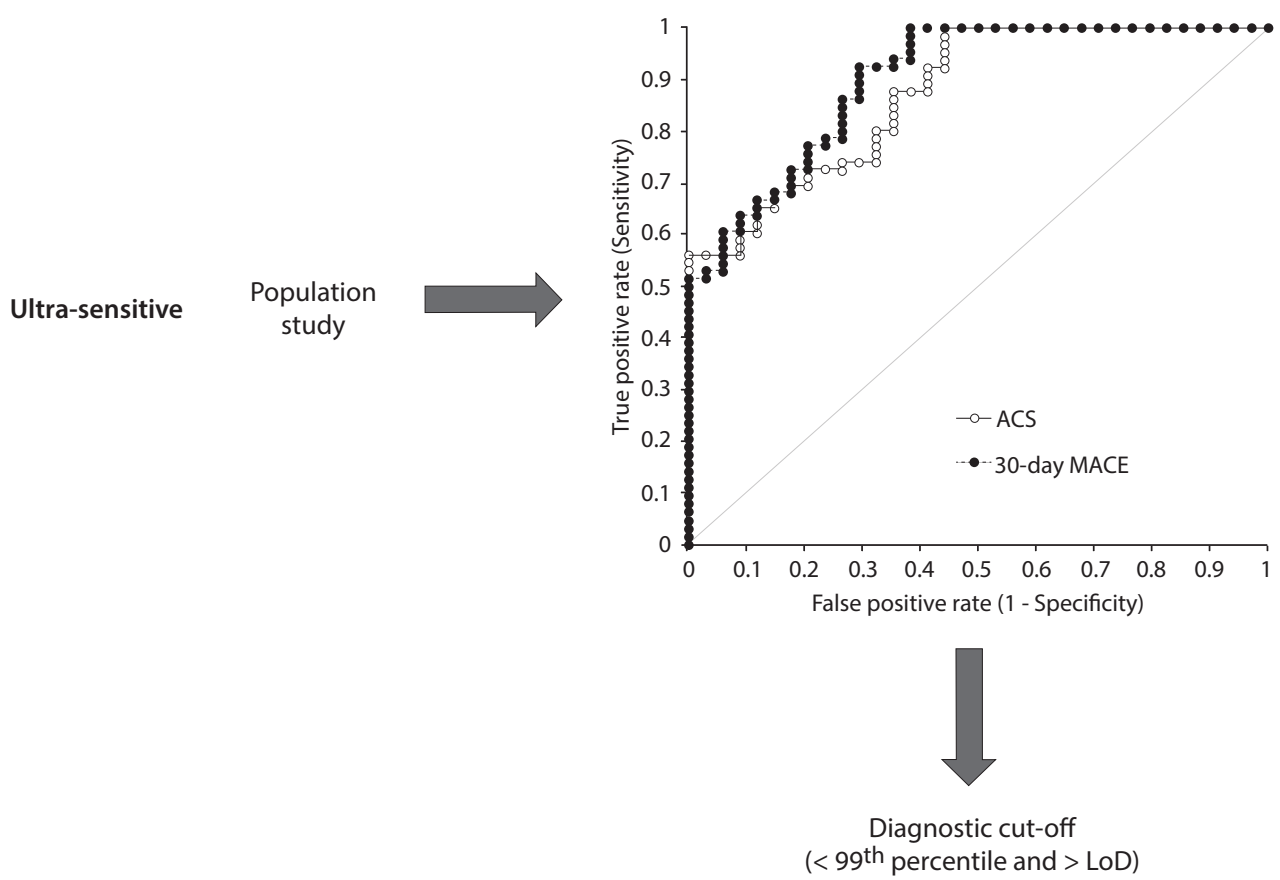

FiguRE 2. Development of cut-offs for diagnostic algorithms including different cardiac troponin immunoassays. CV10\% - coefficient of variation value with $\leq 10 \%$ analytical imprecision (functional sensitivity). LoD - limit of detection. 99th percentile - 99th percentile of a reference healthy population.

$0 \mathrm{~h} / \mathrm{h}$ rule-in and rule-out algorithms, maintaining virtually the same diagnostic efficiency of the conventional $0 \mathrm{~h} / 3 \mathrm{~h}$ algorithms, but also generating a favourable impact, both organizational and economic, for patient management in short stay units such as the emergency room $(13,30,31)$. Notably, $\mathrm{Oh} / 2 \mathrm{~h}$ serial sampling can be seen as a promising and reliable alternative to the shorter $0 \mathrm{~h} / 1 \mathrm{~h}$ strategy, especially suited for those facilities where the $\mathrm{Oh} / \mathrm{h}$ algorithm cannot be straightforwardly implemented due to practical reasons (i.e., the emergency room is far from the core laboratory and/or efficient means of samples transportation such as pneumatic transport system are unavailable) (16).

\section{Conclusions}

In conclusion, the gradual introduction in clinical practice of the so-called "US" cTn immunoassays will need to be anticipated by large and robust clinical studies aimed to identify the most suitable cut-offs and the most appropriate timing for serial sampling to get the most from these new techniques. For the time being, thoughtful translation of current diagnostic algorithms to these "US" and other incoming cTn immunoassays seems unadvisable.

\section{Potential conflict of interest}

None declared. 


\section{References}

1. Sanchis-Gomar F, Perez-Quilis C, Leischik R, Lucia A. Epidemiology of coronary heart disease and acute coronary syndrome. Ann Transl Med. 2016;4:256. https://doi. org/10.21037/atm.2016.06.33

2. Lippi G, Cervellin G. Do we really need high-sensitivity troponin immunoassays in the emergency department? Maybe not. Clin Chem Lab Med. 2014;52:205-12. https://doi. org/10.1515/cclm-2013-0524

3. Thygesen K, Alpert JS, Jaffe AS, Simoons ML, Chaitman $B R$, White $H D$, et al. Third universal definition of myocardial infarction. Circulation. 2012;126:2020-35. https://doi. org/10.1161/CIR.0b013e31826e1058

4. Roffi M, Patrono C, Collet JP, Mueller C, Valgimigli M, Andreotti F, et al. 2015 ESC Guidelines for the management of acute coronary syndromes in patients presenting without persistent ST-segment elevation: Task force for the management of acute coronary syndromes in patients presenting without persistent ST-segment elevation of the European Society of Cardiology (ESC). Eur Heart J. 2016;37:267-315. https://doi. org/10.1093/eurheartj/ehv320

5. Alvin MD, Jaffe AS, Ziegelstein RC, Trost JC. Eliminating creatine kinase-myocardial band testing in suspected acute coronary syndrome: $A$ value-based quality improvement. JAMA Intern Med. 2017;177:1508-12. https://doi. org/10.1001/jamainternmed.2017.3597

6. Armbruster DA, Pry T. Limit of blank, limit of detection and limit of quantitation. Clin Biochem Rev. 2008;29(Suppl 1):S49-52.

7. Apple FS, Jaffe AS, Collinson P, Mockel M, Ordonez-Llanos $J$, Lindahl $B$ et al. IFCC educational materials on selected analytical and clinical applications of high sensitivity cardiac troponin assays. Clin Biochem. 2015;48:201-3. https:// doi.org/10.1016/j.clinbiochem.2014.08.021

8. Apple FS. A new season for cardiac troponin assays: it's time to keep a scorecard. Clin Chem. 2009;55:1303-6. https://doi. org/10.1373/clinchem.2009.128363

9. Galli C, Lippi G. High-sensitivity cardiac troponin testing in routine practice: economic and organizational advantages. Ann Transl Med. 2016;4:257. https://doi.org/10.21037/ atm.2016.07.04

10. Boeckel JN, Palapies L, Zeller T, Reis SM, von Jeinsen B, Tzikas $S$, et al. estimation of values below the limit of detection of a contemporary sensitive troponin I assay improves diagnosis of acute myocardial infarction. Clin Chem. 2015;61:1197206. https://doi.org/10.1373/clinchem.2015.238949

11. Shah AS, Anand A, Sandoval Y, Lee KK, Smith SW, Adamson $P D$, et al. High-sensitivity cardiac troponin I at presentation in patients with suspected acute coronary syndrome: a cohort study. Lancet. 2015;386:2481-8. https://doi. org/10.1016/S0140-6736(15)00391-8

12. Ferencik M, Mayrhofer T, Lu MT, Woodard PK, Truong QA, Peacock WF, et al. High-sensitivity cardiac troponin I as a gatekeeper for coronary computed tomography angiography and stress testing in patients with acute chest pain. Clin Chem. 2017;63:1724-33. https://doi.org/10.1373/ clinchem.2017.275552
13. Lippi G, Bonfanti L, Dipalo M, Aloe R, Cervellin G. Clinical, organizational and economic analysis of high-sensitivity cardiac troponin testing in the emergency department. Ann Res Hosp. 2017;1:14. https://doi.org/10.21037/ arh.2017.09.02

14. Pickering JW, Than MP, Cullen L, Aldous S, Ter Avest E, Body $R$, et al. Rapid rule-out of acute myocardial infarction with a single high-sensitivity cardiac troponin $T$ measurement below the limit of detection: A collaborative meta-analysis. Ann Intern Med. 2017;166:715-24. https://doi.org/10.7326/ M16-2562

15. Sorensen NA, Neumann JT, Ojeda F, Schwemer T, Renne T, Schnabel RB, et al. Challenging the 99th percentile: A lower troponin cutoff leads to low mortality of chest pain patients. Int J Cardiol. 2017;232:289-93. https://doi.org/10.1016/j.ijcard.2016.12.167

16. Cervellin G, Mattiuzzi C, Bovo C, Lippi G. Diagnostic algorithms for acute coronary syndrome-is one better than another? Ann Transl Med. 2016;4:193. https://doi. org/10.21037/atm.2016.05.16

17. Reichlin T, Irfan A, Twerenbold R, Reiter M, Hochholzer W, Burkhalter $H$, et al. Utility of absolute and relative changes in cardiac troponin concentrations in the early diagnosis of acute myocardial infarction. Circulation. 2011;124:136-45. https://doi.org/10.1161/CIRCULATIONAHA.111.023937

18. Boeddinghaus J, Reichlin T, Cullen L, Greenslade JH, Parsonage WA, Hammett $C$, et al. Two-hour algorithm for triage toward rule-out and rule-in of acute myocardial infarction by use of high-sensitivity cardiac troponin I. Clin Chem. 2016;62:494-504. https://doi.org/10.1373/ clinchem.2015.249508

19. Reichlin T, Cullen L, Parsonage WA, Greenslade J, Twerenbold R, Moehring B, et al. Two-hour algorithm for triage toward rule-out and rule-in of acute myocardial infarction using high-sensitivity cardiac troponin T. Am J Med. 2015;128:369-79.e4. https://doi.org/10.1016/j.amjmed.2014.10.032

20. Nestelberger $T$, Wildi $K$, Boeddinghaus $J$, Twerenbold $R_{\text {, }}$ Reichlin T, Gimenez MR, et al. Characterization of the observe zone of the ESC 2015 high-sensitivity cardiac troponin $\mathrm{Oh} / 1 \mathrm{~h}$-algorithm for the early diagnosis of acute myocardial infarction. Int J Cardiol. 2016;207:238-45. https://doi. org/10.1016/j.ijcard.2016.01.112

21. Rubini Giménez M, Hoeller R, Reichlin T, Zellweger C, Twere$n$ bold $R$, Reiter $M$, et al. Rapid rule out of acute myocardial infarction using undetectable levels of high-sensitivity cardiac troponin. Int J Cardiol. 2013;168:3896-901. https://doi. org/10.1016/j.ijcard.2013.06.049

22. Jaeger $C$, Wildi K, Twerenbold R, Reichlin T, Rubini Gimenez $M$, Neuhaus JD, et al. One-hour rule-in and rule-out of acute myocardial infarction using high-sensitivity cardiac troponin I. Am Heart J. 2016;171:92-102.e1. https://doi. org/10.1016/j.ahj.2015.07.022

23. Krintus M, Kozinski M, Boudry P, Capell NE, Koller U, Lackner $K$, et al. European multicenter analytical evaluation of the Abbott ARCHITECT STAT high sensitive troponin I immunoassay. Clin Chem Lab Med. 2014;52:1657-65. https://doi. org/10.1515/cclm-2014-0107 
24. Koerbin G, Tate JR, Hickman PE. Analytical characteristics of the Roche highly sensitive troponin Tassay and its application to a cardio-healthy population. Ann Clin Biochem. 2010;47:524-8. https://doi.org/10.1258/acb.2010.010033

25. Saenger AK, Beyrau R, Braun S, Cooray R, Dolci A, Freidank $H$, et al. Multicenter analytical evaluation of a high-sensitivity troponin T assay. Clin Chim Acta. 2011;412:748-54. https://doi.org/10.1016/j.cca.2010.12.034

26. Lippi G, Ferrari A, Gandini G, Gelati M, Lo Cascio C, Salvagno GL. Analytical evaluation of the new Beckman Coulter Access high sensitivity cardiac troponin I immunoassay. Clin Chem Lab Med. 2017;56:157-61. https://doi.org/10.1515/ cclm-2017-0350

27. Payne RC, Halik L, DiPasquale C, Ma J, Zhang H, Zhang J, et al. Performance evaluation of the high sensitivity cardiac troponin I assay on the ADVIA Centaur XP/XPT immunoassay systems. Eur Heart J. 2017;38(Supp/1):597. https://doi. org/10.1093/eurheartj/ehx502.P2754
28. Lippi G, Salvagno GL, Da Rin G, Giavarina D. Harmonization of contemporary-sensitive troponin I immunoassays: calibration may only be a part of the problem. Riv Ital Med Lab. 2014;10:108-14. https://doi.org/10.1007/s13631-014-00533

29. García-Osuna A, Alquezar-Arbe A, Duran-Cambra A, GrauAlmiral M, Perez-Calleja R, Enkhbayar U, et al. Cardiac troponin I measured with the Singulex Sgx Clarity ${ }^{\mathrm{TM}} \mathrm{CTn}$ I assay: A step forward on high analytical sensitivity. Clin Chem. 2017;63(Suppl10):S23.

30. Ambavane A, Lindahl B, Giannitsis E, Roiz J, Mendivil J, Frankenstein $L$, et al. Economic evaluation of the one-hour rule-out and rule-in algorithm for acute myocardial infarction using the high-sensitivity cardiac troponin $T$ assay in the emergency department. PLoS One. 2017;12:e0187662. https://doi.org/10.1371/journal.pone.0187662

31. Jaeger C, Wildi K, Twerenbold R, Reichlin T, Rubini Gimenez $M$, Neuhaus JD, et al. One-hour rule-in and rule-out of acute myocardial infarction using high-sensitivity cardiac troponin I. Am Heart J. 2016;171:92-102.e1. https://doi. org/10.1016/j.ahj.2015.07.022 